\title{
Diagnosis of right bundle branch block: a concordance study
}

\author{
M. Alventosa-Zaidin ${ }^{*}$, G. Pera ${ }^{2}$, C. Roca Saumell ${ }^{3}$, N. Mengual Miralles ${ }^{4}$, M. V. Zamora Sanchez ${ }^{5}$, T. Gros Garcia ${ }^{4}$, \\ L. Guix Font ${ }^{6}$, M. Benitez Camps ${ }^{5}$, J. Francisco-Pascual ${ }^{7}$ and J. Brugada Terradellas ${ }^{8}$
}

\begin{abstract}
Background: Right bundle branch block is one of the most common electrocardiographic abnormalities. Most cases of right bundle branch block are detected in asymptomatic patients in primary care, so a correct interpretation of electrocardiograms (ECGs) at this level is necessary.

The objective of this research is to determine the degree of concordance in the diagnosis of incomplete and complete right bundle branch block between four primary care researchers and a cardiologist.

Methods: The research design is a retrospective cohort study of patients over 18 years of ages of patients over 18 years of ages who underwent an ECG for any reason and were diagnosed with right bundle branch block by their physician. The physicians participating, 4 primary care researchers and a cardiologist were specialized in interpreting electrocardiographic records. The diagnosis of incomplete and complete right bundle branch block was recorded and other secondary variables were analysed.

In case of diagnostic discordance between the researchers, the ECGs were reviewed by an expert cardiologist, who interpreted them, established the diagnosis and analysed the possible causes for the discrepancy.
\end{abstract}

Results: We studied 160 patients diagnosed with right bundle branch block by their general practise. The patients had a mean age of 64.8 years and $54 \%$ of them were men. The concordance in the diagnosis of incomplete right bundle branch block showed a Fleiss' kappa index ( $k$ ) of 0.71 among the five researchers and of 0.85 among only the primary care researchers. The $k$ for complete right bundle branch block was 0.93 among the five researchers and 0.96 among only the primary care researchers.

Conclusion: The interobserver agreement in the diagnosis of right bundle branch block performed by physicians specialized in ECG interpretation (primary care physicians and a cardiologist) was very good. The variability was greater for the diagnosis of incomplete right bundle branch block.

Keywords: Concordance, Bundle branch block

\section{Background}

Since the introduction of the Minnesota Code [1], several epidemiological studies have been published to determine the prevalence of ECG abnormalities in a standardized way. Most of these studies are based on the middle-aged population, mainly men in certain professions [2] .One of the abnormalities most commonly found is bundle branch block (BBB).

\footnotetext{
*Correspondence: malvenza83@gmail.com

'Bon Pastor, Primary Healthcare Center, Catalan Health Institute, Barcelona, Catalonia, Spain

Full list of author information is available at the end of the article
}

The heart's natural pacemaker is the sinus node, which sends the electrical impulses to the atrioventricular node. From there the impulses are transmitted to the ventricles through the right and left branches of the His bundle (through Purkinje fibres). The ECG QRS complex indicates ventricular depolarization and under normal conditions is less than $120 \mathrm{~ms}$.

When BBB occurs, one branch of the His bundle delays conducting the electrical impulse and the ventricle is activated by the myocardial propagation of the electrical activity of the other ventricle. Thus, the affected ventricle is depolarized erratically and slowly through an alternative pathway. This delay is shown in the ECG

(c) The Author(s). 2019 Open Access This article is distributed under the terms of the Creative Commons Attribution 4.0 International License (http://creativecommons.org/licenses/by/4.0/), which permits unrestricted use, distribution, and reproduction in any medium, provided you give appropriate credit to the original author(s) and the source, provide a link to the Creative Commons license, and indicate if changes were made. The Creative Commons Public Domain Dedication waiver (http://creativecommons.org/publicdomain/zero/1.0/) applies to the data made available in this article, unless otherwise stated. 
with a widening of the QRS complex (duration $>120$ $\mathrm{ms}$ ) and a change of its pattern, which varies depending on the affected branch.

One of the most frequent alterations of the ECG is Right bundle branch block (RBBB). [3]

Many studies have showed the association between RBBB with CV diseases [4] (cor pulmonale, myocarditis, acute myocardial infarction [AMI], pulmonary thromboembolism and congenital diseases) and this relation increases the $\mathrm{CV}$ morbidity and mortality. The new appearance of RBBB immediately after AMI therefore involves an increase in mortality [5]; and in patients hospitalized for exacerbated heart failure (HF) worsens their prognosis [6].

RBBB has been also associated with CVRF such as hypertension and diabetes mellitus $[7,8]$.

The impact of RBBB in patients with no history of CV disease is still controversial. Some studies have shown that RBBB increases CV events, with results not always statistically significant [9], or are only significant for a specific CV event $[10,11]$. Whereas others studies have reported no risk $[9,12,13]$.

There is no unanimous consensus on the diagnostic criteria of RBBB in the literature. All studies use a 12-lead standard ECG at rest, but there is no agreement on the wave abnormalities or their duration. Some studies use the diagnostic criteria of the Minnesota Code [10-16], but others and clinical practice guidelines use less stringent criteria [17-20].

The implications of detecting BBB, especially in prognosis, mean that ECG readings must be performed carefully for the conclusions to be valid. The articles cited above show great variation with regard to the correct interpretation of ECG by primary care physicians [21, 22].

After a thorough review of the literature, we found no studies that assess the degree of concordance of the diagnosis of RBBB between primary care (PC) physicians and cardiologists. Therefore, the aim of our study was to investigate the degree of concordance for the diagnosis of RBBB between 4 PC researchers and one cardiologist.

\section{Methods}

The research design was a retrospective cohort study of patients over 18 years of ages. A concordance study was performed at an urban health centre in Barcelona. The ECG sample for the study was drawn from 3614 electrocardiographic records of 2147 adult patients in whom an ECG was recorded for any reason at the health centre during an 8-year period (2007 to 2015). Of the ECGs, $13.8 \%(N=261)$ were interpreted by their PC physician as showing RBBB. Of these, we chose the ECGs that were well preserved to facilitate the interpretation of the researchers, resulting in a total of 160 ECGs. The remaining 101 ECG could not be used for being unreadable.
The 160 selected ECGs were given to the investigators of the project, who were not related to the centre where the ECGs had been recorded: 4PC physicians with special training in ECG interpretation and a cardiologist.

All researchers were unaware of the initial ECG diagnosis performed by the patient's family physician, of the electrocardiographic record diagnosed by the other researchers, and of the automated analysis performed by the software.

\section{Assessment of RBBB in the ECGs}

Before the researchers started to read the ECGs, the diagnostic criteria of complete RBBB (cRBBB) and incomplete RBBB (iRBBB) were agreed among all the participating researchers on the basis of the literature and clinical practice guidelines, in addition to the criteria of other abnormalities recorded: heart rhythm, heart rate, $\mathrm{P}$ wave duration, QRS duration, Cornell product, left bundle branch block (LBBB), left anterior and posterior hemiblock, atrioventricular block, bifascicular and trifascicular block, and atrial fibrillation.

Given the diversity of diagnostic criteria of RBBB, in the protocol the presence of $\mathrm{CRBBB}$ and $\mathrm{iRBBB}$ was defined using the most widely used criteria, which are shown in Fig. 1.

Patients with BBB with an rsr' pattern in leads V1 and/or V2 but with a QRS duration of less than $100 \mathrm{~ms}$ were not labelled as having iRBBB, although in some studies they are considered as such. These patients were classified as patients with an rsr' pattern but without diagnosis of iRBBB. The diagnostic criteria of other variables analysed are defined in Table 1.

The ECGs were interpreted individually by each researcher, who, after reading the electrocardiographic records, introduced in the database the presence or absence of RBBB, as well as the other parameters mentioned above. The data were later analysed centrally by a statistician who did not know who had interpreted the ECGs.

The ECGs that presented a diagnostic discordance (both CRBBB and iRBBB) between the five researchers (4 PC and the cardiologist) were reviewed by an expert cardiologist, who established the diagnosis and analysed the possible causes for the electrocardiographic misinterpretation.

\section{Statistical analysis}

Each ECG was rated by 6 physicians (the 5 researchers and the PC physician who had performed the initial diagnosis). For the main variables (cRBBB or iRBBB), 6 diagnoses were obtained that could be coincident or not. The secondary variables were only analysed by the 5 medical researchers because we did not have the information from the patient's family doctor. To establish the degree of concordance between the raters, for both the diagnosis of 


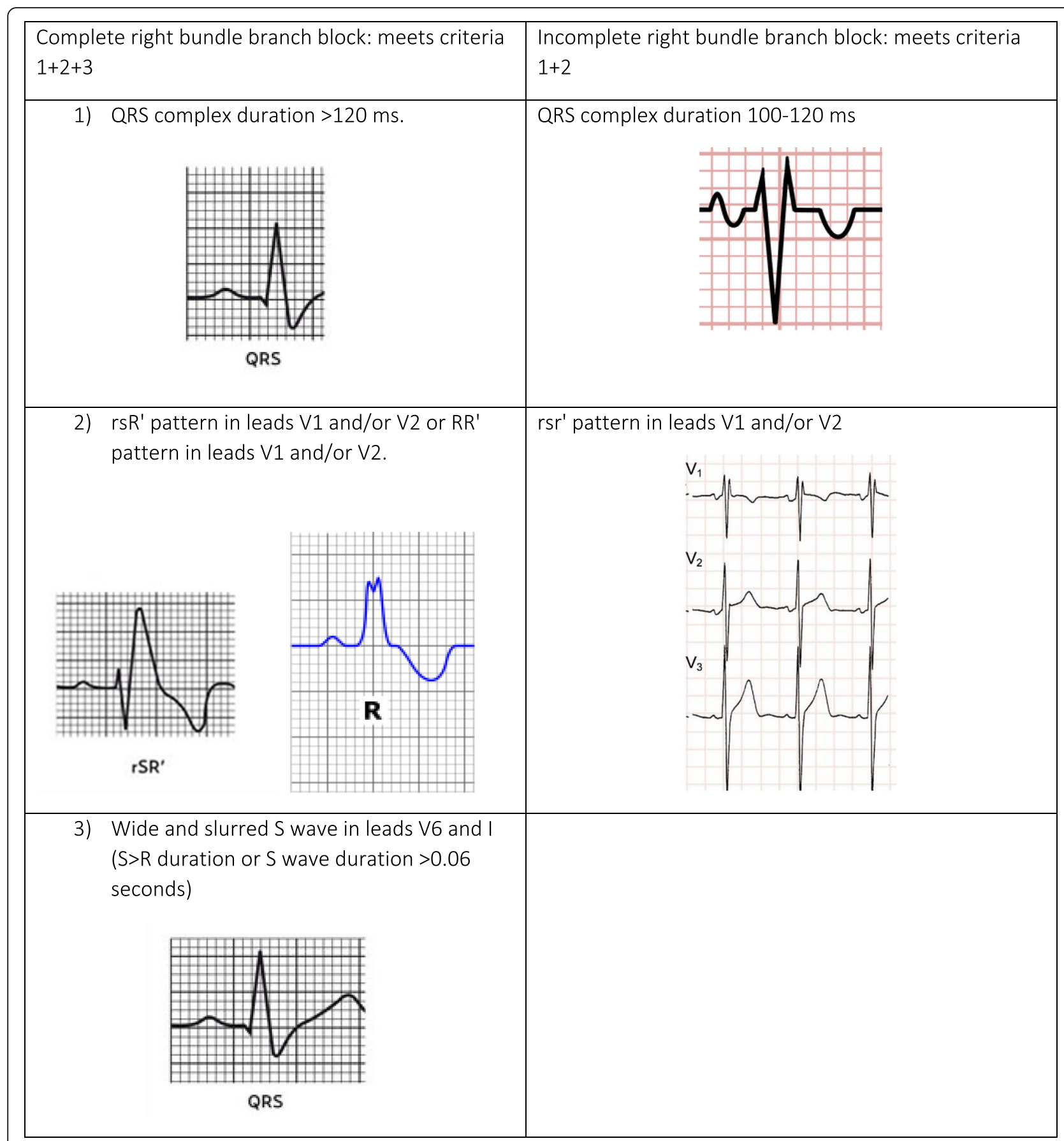

Fig. 1 Diagnostic criteria for right bundle branch block ${ }^{18,19}$

RBBB and the secondary variables analysed we used the Fleiss' Kappa index $(k)$ and its 95\% confidence interval [23] For the continuous variables we used the interclass correlation coefficients (ICC).

For descriptive purposes, we present the box diagrams of the continuous variables evaluated by the 5 researchers. We used the Stata 14 statistical package for all the analyses.

\section{Results}

Of the 160 patients with ECGs analysed, 54\% were men. The mean age of the sample was 64.8 years (range, 1897 years).

The results of the concordance between the PC physicians (who had made the initial diagnosis of RBBB) and the 5 investigators are shown in Table 2. The concordance between the diagnosis of the patients' family 
Table 1 Secondary variables analysed

\begin{tabular}{|c|c|}
\hline Variable & Description \\
\hline Sinus rhythm & $\begin{array}{l}\text { Regular PP interval } \\
\text { Heart rate } 60-100 \text { bpm, P waves positive } \\
\text { in lead II and negative in lead aVR } \\
\text { PR interval constant ( } 120-200 \mathrm{~ms})\end{array}$ \\
\hline Electrocardiographic axis & Bayes de Luna criteria (34) \\
\hline $\begin{array}{l}\text { P wave duration, PR interval } \\
\text { and QRS duration }\end{array}$ & In ms \\
\hline $\begin{array}{l}\text { Left ventricular hypertrophy } \\
(\mathrm{LVH})\end{array}$ & $\begin{array}{l}\text { Cornell index in } \mathrm{mm}: \mathrm{R} \text { in lead } \mathrm{aVL}+\mathrm{S} \text { in } \\
\text { lead } \mathrm{V} 3 \text {. Positive: } \\
>28 \mathrm{~mm} \text { in men } \\
>20 \mathrm{~mm} \text { in women }\end{array}$ \\
\hline $\begin{array}{l}\text { Left bundle branch block } \\
\text { (LBBB) }\end{array}$ & $\begin{array}{l}\text { M-shaped QRS complexes (RR') in leads } \\
\text { V5, V6, I and aVL. } \\
\text { Wide and slurred S wave in lead V5 and/ } \\
\text { or V6. QRS complex duration > } 120 \mathrm{~ms} \text { : } \\
\text { complete } \\
\text { QRS complex duration 100-120 ms: } \\
\text { incomplete }\end{array}$ \\
\hline $\begin{array}{l}\text { Left anterior hemiblock } \\
\text { (LAH) }\end{array}$ & $\begin{array}{l}\text { Marked left axis deviation } \geq-30^{\circ} \\
\text { Q1-SII-SIII pattern with wave SIII>SII. } \\
\text { Typical rS pattern in leads II, III, aVF and } \\
\text { qR in leads I, aVL. }\end{array}$ \\
\hline $\begin{array}{l}\text { Left posterior hemiblock } \\
(\mathrm{LPH})\end{array}$ & $\begin{array}{l}\text { Marked right axis deviation }>120^{\circ} \\
\text { S1-QII-QIII pattern with wave RIII>RII. } \\
\text { Normal QRS complex duration. }\end{array}$ \\
\hline Bifascicular block & $\begin{array}{l}\text { RBBB with LAH: RBBB pattern } \\
(\text { QRS }>120 \mathrm{~ms})+\text { left axis deviation }<-30^{\circ} \text {. }\end{array}$ \\
\hline & $\begin{array}{l}\text { RBBB with LPH: RBBB pattern (QRS }>120 \\
m s)+ \text { right axis deviation }<-120^{\circ} .\end{array}$ \\
\hline Trifascicular block & $\begin{array}{l}\text { Bifascicular block plus first-degree AV } \\
\text { block. }\end{array}$ \\
\hline Atrioventricular block (AVB) & $\begin{array}{l}\text { First-degree AVB: Constant PR interval } \\
\text { with duration > } 200 \text { ms. } \\
\text { Type I second-degree AVB: progressive } \\
\text { lengthening of the PR interval until a beat } \\
\text { is dropped. } \\
\text { Type II second degree AVB: intermittent } \\
\text { block of AV conduction without } \\
\text { lengthening of the PR interval. } \\
\text { Third-degree AVB: complete absence of } \\
\text { conduction between the atria and the } \\
\text { ventricles. P and QRS complexes follow } \\
\text { an independent rhythm. }\end{array}$ \\
\hline $\begin{array}{l}\text { Cardiac arrhythmia due to } \\
\text { atrial fibrillation (CAAF) }\end{array}$ & $\begin{array}{l}\text { Absence of P waves } \\
\text { Presence of irregular F waves (not always } \\
\text { visible) } \\
\text { Rapid frequencies and QRS complexes } \\
\text { normal and arrhythmic (irregular PR } \\
\text { interval). }\end{array}$ \\
\hline
\end{tabular}

doctors and the cardiologist was worse than that between the family doctors and the 4 PC researchers, though in both cases it was better for cRBBB than for iRBBB.

The concordance for the ECG parameters between the 4 PC researchers and the cardiologist can be seen in Table 3. Again, the concordance was better for cRBBB and among the PC physicians. Regarding the continuous variables obtained from the ECGs, the ICCs were high, and they were higher between the 4 PC researchers than when the cardiologist was included. Figure 2 shows the box diagrams of these variables for the 5 researchers, with few differences between them.

Those ECGs that presented a diagnostic discordance (for both CRBBB and iRBBB) between the researchers were reviewed by an expert cardiologist, who established the diagnosis and analysed the possible causes of interpretation error.

There were 41 cases of discrepancy between the researchers in the iRBBB group. In 24 of them the discordance was between the cardiologist and the $4 \mathrm{PC}$ researchers and in the remaining 17 ECGs it occurred between at least 2 researchers.

In the cRBBB group, there were 11 cases of discrepancy between the researchers. In 5 ECGs the different diagnosis was made between the cardiologist and the 4 $\mathrm{PC}$ researchers and, in the remaining 6 , between at least 2 researchers. The description of the discordant ECGs and their causes are detailed in Table 4.

\section{Discussion}

\section{Summary}

ECG is currently a routine clinical practice, not only in patients with clinical signs of myocardial damage (acute phases of cardiac pathology), but also in the general population for early detection of cardiovascular disease or risk factors. Clinical decisions following an ECG are dependent on the severity of the abnormalities found or the prognosis.

One of the most frequent abnormalities found is $B B B$, predominantly RBBB. RBBB is more frequent than LBBB because the Purkinje fibres of the right bundle branch have a longer, thinner structure than those of the left bundle branch. Therefore, minimal abnormalities in the Purkinje fibres, such as age-related degeneration, block the conduction of the right bundle branch [24].

Table 2 Concordance between the PC physicians and the researchers

\begin{tabular}{llll}
\hline Variable & \multicolumn{2}{l}{ Degree of concordance (Fleiss' kappa index and 95\% Cl) } \\
\cline { 2 - 4 } & PC physicians and the 5 researchers & PC physicians and the cardiologist & PC physicians and the 4 PC researchers \\
\hline iRBBB & $0.50(0.46-0.54)$ & $0.25(0.13-0.37)$ & $0.54(0.49-0.59)$ \\
CRBBB & $0.88(0.84-0.92)$ & $0.72(0.57-0.87)$ & $0.89(0.84-0.94)$ \\
\hline
\end{tabular}


Table 3 Concordance between the 4 PC researchers and the cardiologist and among the 4 PC researchers

\begin{tabular}{lll}
\hline Variable & $\begin{array}{l}\text { Concordance between 4 PC researchers } \\
\text { and the cardiologist. }\end{array}$ & $\begin{array}{l}\text { Concordance between the four } \\
\text { PC physicians }\end{array}$ \\
\hline $\begin{array}{l}\text { Primary variable } \\
\text { iRBBB }\end{array}$ & $0.71(0.66-0.76)$ & $0.85(0.79-0.91)$ \\
CRBBB & $0.93(0.88-0.98)$ & $0.96(0.90-1.0)$ \\
Secondary variables & & $0.77(0.71-0.83)$ \\
Heart rhythm & $0.75(0.70-0.80)$ & $0.98(0.97-0.98)$ \\
Heart rate & $0.96(0.95-0.97)$ & $0.89(0.86-0.91)$ \\
Axis & $0.86(0.82-0.89)$ & $0.84(0.80-0.88)$ \\
P wave duration & $0.70(0.61-0.77)$ & $0.98(0.98-0.99)$ \\
QRS complex duration & $0.96(0.95-0.97)$ & $0.97(0.96-0.98)$ \\
PR interval duration & $0.94(0.93-0.96)$ & $0.89(0.86-0.92)$ \\
Cornell index: left ventricular hypertrophy (LVH) & $0.88(0.86-0.91)$ & $0.82(0.76-0.88)$ \\
Left anterior hemiblock (LAH) & $0.82(0.77-0.87)$ & $0.16(0.10-0.22)$ \\
Left posterior hemiblock (LPH) & $0.24(0.19-0.29)$ & $0.81(0.75-0.87)$ \\
Bifascicular block & $0.79(0.74-0.84)$ & $0.76(0.70-0.82)$ \\
Trifascicular block & $0.74(0.69-0.79)$ & $0.73(0.67-0.79)$ \\
Atrioventricular block (AVB) & $0.69(0.64-0.74)$ & $0.84(0.78-0.90)$ \\
Cardiac arrhythmia due to atrial fibrillation (CAAF) & $0.82(0.77-0.87)$ & \\
\hline
\end{tabular}

Results are intraclass correlation coefficients ( $95 \%$ confidence interval)

\section{Strengths and limitations}

Following the criteria of Landis and Koch [25] this study shows a level of concordance between good and very good among the $\mathrm{PC}$ researchers and the cardiologist for the diagnosis of RBBB. However, note that this criteria is arbitrary, although the closer $\mathrm{k}$ is to 1 the greater the agreement, specially if the number of categories is fixed, as it was. The concordance between the 5 researchers and the PC physicians who had made the initial diagnosis was worse than the concordance between the 5 researchers and the cardiologist.

Furthermore, for the secondary variables analysed, the concordance between the PC researchers and the cardiologist was also good or very good. However, this was not the case with concordance for posterior hemiblock, perhaps because the interpretation of the kappa index depends on the prevalence of the variable studied. In our study, only 3 cases were detected, one diagnosed by 3 researchers and the other 2 diagnosed by 2 researchers.

Most studies of the degree of competence of PC physicians in ECG interpretation are concordance studies between these physicians and cardiologists. This approach involves limitations, because there is also variability in the interpretation of the electrocardiographic abnormalities among cardiologists, and in the same cardiologist when an ECG is interpreted several times. This is a limiting factor in our study, so we also evaluated the degree of concordance among the 4 PC researchers but found no significant differences from the comparison with the cardiologist.
When we analyse the data of the ECGs with the electrocardiographic interpretation of the expert cardiologist, it is shown that, for the diagnosis of $\mathrm{CRBBB}$, the expert cardiologist interpretation always matches the one made by the cardiologist on the initial analysis. For the $\mathrm{iRBBB}$ group, the expert cardiologist matches in some cases with the diagnosis of the PC researchers or with the initial cardiologist in others.

The main reason for the observed differences could be that the lecture of the ECGs was made manually, causing differences on the QRS complex duration, changes in the block morphology (the presence of r' would not be clear) and, in some cases of discordance in iRBBB, the axis showed a left deviation and therefore the diagnosis was a left branch hemiblock.

Our study suggests that continuous education in ECG interpretation is a very effective tool for decreasing diagnostic variability and improving the competence of non-cardiologist physicians. However, we were unable to establish that it is the cause of the improved results, because we did not evaluate the concordance between the PC researchers and the cardiologist before and after the training and because the level of training of the PC physicians who had performed the initial diagnosis of RBBB was unknown.

The concordance results may have been overestimated because the researchers were better informed merely from participating in the study and because of the effect of the study design. It should be taken into 

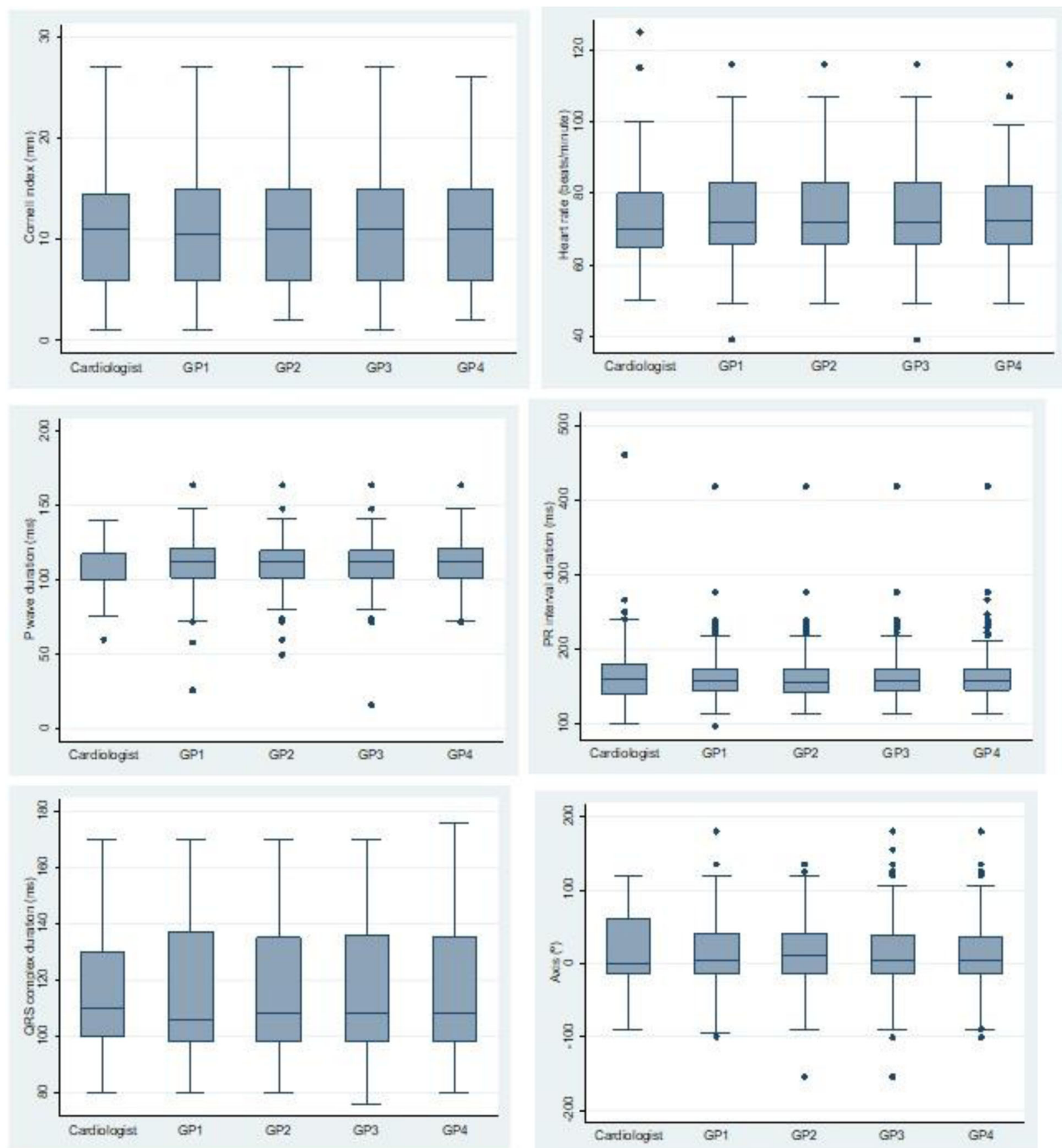

Fig. 2 Box diagrams of Cornell index, heart rate, P wave, PR interval duration, QRS complex and axis, among the 5 researchers

account that the researchers may have found it easier to know and have available diagnostic criteria for RBBB than physicians working in usual day-to-day practice in PC or hospital consultation. Furthermore, the fact that only the best- preserved ECGs were chosen may constitute a selection bias, since in daily practice the quality of the electrocardiographic records is very variable.

\section{Comparison with existing literature and knowledge}

Studies evaluating the correct interpretation of ECGs by general practitioners when compared with the diagnoses performed by cardiologists have shown that correct results are obtained in 36 to $96 \%$ of cases [21,22]. Many studies consider the diagnostic capacity for a particular pathology. Some studies have observed that non-specialists in cardiology identify between 87 and $100 \%$ of myocardial 
Table 4 Expert Cardiologist analysis of the discordant ECGs between the 5 researchers

\begin{tabular}{|c|c|c|c|c|}
\hline \multicolumn{5}{|l|}{ CRBBB } \\
\hline DISCORDANCE & $1 P C$ & $3 P C+i C$ & $\mathrm{EC}$ & Etiophatology \\
\hline 1 & 1 YES & $1 \mathrm{NO}$ & $1 \mathrm{NO}$ & QRS complex duration \\
\hline DISCORDANCE & $2 \mathrm{PC}$ & $2 \mathrm{PC}+\mathrm{iC}$ & EC & Etiophatology \\
\hline 2 & 2 YES & $2 \mathrm{NO}$ & $2 \mathrm{NO}$ & $\begin{array}{l}1 \text { Axis } \\
1 \text { Morphology }\end{array}$ \\
\hline 3 & $3 \mathrm{NO}$ & 3 YES & $\begin{array}{l}2 \mathrm{NO} \\
1 \text { YES }\end{array}$ & $\begin{array}{l}2 \text { Axis } \\
1 \text { QRS complex duration }\end{array}$ \\
\hline DISCORDANCE & $3 P C$ & $1 P C+i C$ & EC & Etiophatology \\
\hline- & - & - & - & - \\
\hline DISCORDANCE & $4 P C$ & iC & EC & Etiophatology \\
\hline 4 & $4 \mathrm{NO}$ & 4 YES & 4 YES & 4 QRS duration \\
\hline 1 & 1 YES & $1 \mathrm{NO}$ & $1 \mathrm{NO}$ & 1 Morphology \\
\hline \multicolumn{5}{|l|}{ iRBBB } \\
\hline DISCORDANCE & $1 P C$ & $3 P C+i C$ & $\mathrm{EC}$ & Etiophatology \\
\hline 8 & 8 YES & $8 \mathrm{NO}$ & $\begin{array}{l}1 \text { YES } \\
7 \mathrm{NO}\end{array}$ & $\begin{array}{l}1 \text { Morphology } \\
4 \text { Morphology } \\
3 \text { Axis }\end{array}$ \\
\hline 2 & $2 \mathrm{NO}$ & 2 YES & $2 \mathrm{NO}$ & $\begin{array}{l}1 \text { Axis } \\
1 \text { Morphology }\end{array}$ \\
\hline DISCORDANCE & $2 \mathrm{PC}$ & $2 P C+i C$ & EC & Etiophatology \\
\hline 6 & $6 \mathrm{NO}$ & 6 YES & $\begin{array}{l}1 \text { YES } \\
5 \mathrm{NO}\end{array}$ & $\begin{array}{l}1 \text { Morphology } \\
4 \text { Morphology } \\
1 \text { Axis }\end{array}$ \\
\hline 1 & 1 YES & $1 \mathrm{NO}$ & $1 \mathrm{NO}$ & 1 Morphology \\
\hline DISCORDANCE & $3 P C$ & $1 P C+i C$ & EC & Etiophatology \\
\hline- & - & - & - & - \\
\hline DISCORDANCE & $4 P C$ & iC & EC & Etiophatology \\
\hline 14 & 14 YES & $14 \mathrm{NO}$ & $\begin{array}{l}9 \text { YES } \\
5 \text { NO }\end{array}$ & $\begin{array}{l}13 \text { Morphology } \\
1 \text { QRS complex duration }\end{array}$ \\
\hline 10 & 10 YES & $10 \mathrm{NO}$ & $\begin{array}{l}5 \text { YES } \\
5 \mathrm{NO}\end{array}$ & $\begin{array}{l}9 \text { Morphology } \\
1 \text { Axis }\end{array}$ \\
\hline
\end{tabular}

PC Primary care researchers

iC Cardiologist who made initial diagnosis

EC Expert Cardiologist

ischemia [26], between 72 and 94\% correctly classify patients who are candidates to receive thrombolytic treatment [27], between 57 and 95\% detect abnormalities in the ST interval [28], and $25 \%$ perform correct interpretations of the PR and QT intervals [29].

There are discrepancies in assessing the impact on morbidity and mortality secondary to misinterpretation or non-identification of ECG abnormalities. In a systematic review, Salerno et al. [30], reported that the amount of diagnostic errors is between 4 and $33 \%$ but the incidence of secondary adverse effects is less than $1 \%$. Other studies warn of the lack of competence of non-cardiologist physicians for detecting lethal electrocardiographic abnormalities that lead to an increase in avoidable cardiac morbidity and mortality [31, 32]. Prospective studies are necessary to evaluate the effect of RBBB in patients with no underlying cardiovascular disease. In patients with a history of cardiovascular disease, the presence of RBBB worsens the prognosis, so failure to identify it may have consequences for the patients.

\section{Implications for practice}

The treatment and prevention of cardiovascular disease is one of the priority objectives in the daily work of the $\mathrm{PC}$ physician. Most cases of $\mathrm{RBBB}$ are detected in asymptomatic patients in $\mathrm{PC}$, so a correct interpretation of the electrocardiograms (ECG) at this level is necessary.

Many studies [5, 33] show that the occurrence of RBBB immediately after a myocardial infarction almost doubles the risk of death, and this risk is higher than that of concomitant LBBB. Also, the appearance of RBBB in patients with heart failure who previously did have it worsens their prognosis $[34,35]$. The clinical significance of $\mathrm{RBBB}$ in a patient with no evidence of any known cardiovascular $(\mathrm{CV})$ pathology is a source of controversy.

Prospective studies are needed to evaluate the impact of RBBB in patients without baseline cardiovascular disease. If it is concluded that RBBB increases cardiovascular morbidity and mortality in healthy patients, it will be necessary to have new guidelines for treating and monitoring these patients.

\section{Conclusions}

Our study shows that interobserver agreement in the diagnosis of RBBB performed by physicians specialized in ECG interpretation (both PC physicians and cardiologists) is very good. The variability is greater for the diagnosis of $\mathrm{iRBBB}$, since there is greater diversity in the diagnostic criteria regarding the duration of the QRS complex. Unifying the criteria would help achieve a better diagnosis so that additional examinations can be made when necessary.

\section{Abbreviations}

AVB: Atrioventricular block; BBB: Bundle branch block; CRBBB: Complete right bundle brunch block; ECG: Electrocardiogram; ICC: Correlation coefficients; iRBBB: Incomplete right bundle brunch block; k: Kappa index; LAH: Left anterior hemiblock; LBBB: Left bundle branch block; LPH: Left posterior hemiblock; LVH: Left ventricular hypertrophy; PC: Primary care; RBBB: Right bundle brunch block

\section{Acknowledgements \\ A Vall-llosera Moll de Alba is thanked for her help in preparing the manuscript.}

\section{Funding}

Funding for the article were provided by many research grants:

\footnotetext{
- 12th grant for research in Primary Care from the Catalan Society of Family Medicine (CAMFIC). (2012)
} 
- Research scholarship for the accomplishment of the doctorate in primary care from University Institute for Research in Primary Care (IDIAP) Jordi Gol. (2014)

- Gonçal Calvo Research Scholarship from the Academy of Medical and Health Sciences of Catalonia and the Balearic Islands (filial Maresme). (2015).

- Research scholarship for primary care professionals of the Catalan Health Institute (area Barcelona city). (2017)

The funders played no role in the study design, data collection and analysis, the decision to publish, or the preparation of the manuscript.

\section{Availability of data and materials}

The datasets used and/or analysed during the current study are available from the corresponding author on reasonable request.

\section{Authors' contributions}

MAZ: made substantial contributions to conception and design, acquisition of data, analysis and interpretation of data and she was involved in drafting the manuscript. GP: made contributions in analysis and interpretation of data. CRS: was involved in drafting the manuscript and revising it critically for important intellectual content. NMM: made contributions in analysis and interpretation of the data from the ECG of the patients. MVZS: made contributions in analysis and interpretation of the data from the ECG of the patients. TGG: made contributions in analysis and interpretation of the data from the ECG of the patients. LGF: was involved in drafting the manuscript and revising it critically for important intellectual content. MBC: was involved in drafting the manuscript and revising it critically for important intellectual content. JFP: made contributions in analysis and interpretation of the data from the ECG of the patients. JB: was involved in drafting the manuscript and revising it critically for important intellectual content. All authors read and approved the final manuscript.

\section{Ethics approval and consent to participate}

The ECGs were encrypted, so each ECG was assigned a random number in the database, which did not allow the identification of the patient. In no case were names, surnames or any data that could identify the patient. No clinical data from patients are used during the study. In this way, according to the Spanish Organic Law of Protection of Personal Data the informed consent of the patients was not necessary.

The study protocol was reviewed and approved by the ethics committee of the Jordi Gol i Gurina Foundation, under registration number FAP 1204

\section{Consent for publication}

Not applicable

\section{Competing interests}

The authors declare that they have no competing interests.

\section{Publisher's Note}

Springer Nature remains neutral with regard to jurisdictional claims in published maps and institutional affiliations.

\footnotetext{
Author details

${ }^{1}$ Bon Pastor, Primary Healthcare Center, Catalan Health Institute, Barcelona, Catalonia, Spain. ${ }^{2}$ Unitat de Suport a la Recerca Metropolitana Nord, Fundació Institut Universitari per a la recerca a l'Atenció Primària de Salut Jordi Gol i Gurina (IDIAPJGol), Mataró, Spain. ${ }^{3}$ EAP El Clot, Primary Healthcare Center, Catalan Health Institute, University of Barcelona, Barcelona, Spain. ${ }^{4}$ EAP Ronda Cerdanya, Primary Healthcare Center, Catalan Health Institute, Mataró, Barcelona, Spain. ${ }^{5}$ EAP El Gòtic, Primary Healthcare Center, Catalan Health Institute, Barcelona, Spain. ${ }^{6}$ EAP Berga, Primary Healthcare Center, Catalan Health Institute, Berga, Barcelona, Spain. ${ }^{7}$ Unity of arithmies. Servei de cardiologia. University Hospital Vall Hebrón, Research Institut, Universitat Autònoma de Barcelona, CIBER-CV, Barcelona, Spain. ${ }^{8}$ Cardiovascular Institute, Hospital Clínic, University of Barcelona, Catalonia, Spain.
}

Received: 8 September 2017 Accepted: 15 April 2019

Published online: 06 May 2019

\section{References}

1. Prineas R, Blackbum HCR. The Minnesota code manual of electrocardiographic findings: standards and procedures for measurement and classification. Minnesota code man Electrocardiogr find stand Proced Meas Classif. 2010.

2. Rose G, Baxter PJ, Reid DD, McCartney P. Prevalence and prognosis of electrocardiographic findings in middle-aged men. Br Heart J. 1978;40: 636-43.

3. De Bacquer D, De Backer G, Kornitzer M. Prevalences of ECG findings in large population based samples of men and women. Heart. 2000;84:625-33.

4. Fernández-Lozano I, Brugada J. Right bundle branch block: are we looking in the right direction? Eur Heart J. 2013;34:86-8.

5. Lewinter C, Torp-Pedersen C, Cleland JGF, Køber L. Right and left bundle branch block as predictors of long-term mortality following myocardial infarction. Eur J Heart Fail. 2011;13:1349-54.

6. Barsheshet A, Goldenberg I, Garty M, Gottlieb S, Sandach A, LaishFarkash A, et al. Relation of bundle branch block to long-term (fouryear) mortality in hospitalized patients with systolic heart failure. Am J Cardiol. 2011;107:540-4

7. Thrainsdottir IS, Hardarson T, Thorgeirsson G, Sigvaldason H, Sigfusson N. The epidemiology of right bundle branch block and its association with cardiovascular morbidity--the Reykjavik study. Eur Heart J. 1993;14:1590-6.

8. Jeong JH, Kim JH, Park YH, Han DC, Hwang KW, Lee DW, et al. Incidence of and risk factors for bundle branch block in adults older than 40 years. Korean J Intern Med. 2004;19:171-8.

9. Haataja P, Anttila I, Nikus K, Eskola M, Huhtala H, Nieminen T, et al. Prognostic implications of intraventricular conduction delays in a general population: the health 2000 survey. Ann Med. 2015;47:74-80.

10. Nielsen JB, Olesen MS, Tangø M, Haunsø S, Holst AG, Svendsen JH. Incomplete right bundle branch block: a novel electrocardiographic marker for lone atrial fibrillation. Europace. 2011;13:182-7.

11. Bussink BE, Holst AG, Jespersen L, Deckers JW, Jensen GB, Prescott E. Right bundle branch block: prevalence, risk factors, and outcome in the general population: results from the Copenhagen City heart study. Eur Heart J. 2013; 34(2):138-46.

12. Fleg JL, Das DN, Lakatta EG. Right bundle branch block: long-term prognosis in apparently healthy men. J Am Coll Cardiol. 1983;1:887-92.

13. Liao YL, Emidy LA, Dyer A, Hewitt JS, Shekelle RB, Paul O, et al. Characteristics and prognosis of incomplete right bundle branch block: an epidemiologic study. J Am Coll Cardiol. 1986;7:492-9.

14. Eriksson P, Wilhelmsen $L$, Rosengren A. Bundle-branch block in middle-aged men: risk of complications and death over 28 years. The primary prevention study in Göteborg, Sweden. Eur Heart J. 2005;26:2300-6.

15. Zhang ZM, Rautaharju PM, Soliman EZ, Manson JE, Cain ME, Martin LW, et al. Mortality risk associated with bundle branch blocks and related repolarization abnormalities (from the Women's health initiative [WHI]). Am J Cardiol. 2012;110:1489-95.

16. Badheka AO, Singh V, Patel NJ, Deshmukh A, Shah N, Chothani A, et al. QRS duration on electrocardiography and cardiovascular mortality (from the National Health and nutrition examination survey_III). Am J Cardiol. 2013; 112:671-7

17. Kusumoto $\mathrm{S}$, Kawano $\mathrm{H}$, Makita N, Ichimaru S, Kaku T, Haruta D, et al. Right bundle branch block without overt heart disease predicts higher risk of pacemaker implantation: the study of atomic-bomb survivors. Int J Cardiol. 2014;174:77-82

18. Xiong Y, Wang L, Liu W, Hankey GJ, Xu B, Wang S. The prognostic significance of right bundle branch block: a meta-analysis of prospective cohort studies. Clin Cardiol. 2015;38:604-13.

19. Schneider JF, Thomas HE, Kreger BE, McNamara PM, Sorlie P, Kannel WB. Newly acquired right bundle-branch block: the Framingham study. Ann Intern Med. 1980;92:37-44

20. Smith RF, Jackson DH, Harthorne JW, Sanders CA. Acquired bundle branch block in a healthy population. Am Heart J. 1970;80:746-51.

21. Todd KH, Hoffman JR, Morgan MT. Effect of cardiologist ECG review on emergency department practice. Ann Emerg Med. 1996;27:16-21.

22. Goodacre S, Webster A, Morris F. Do computer generated ECG reports improve interpretation by accident and emergency senior house officers? Postgrad Med J. 2001;77:455-7. 
23. Fleiss JL, Levin B, Paik MC. Statistical methods for rates and proportions. 3rd ed. New York: Wiley-Interscience; 2003.

24. Eriksson P, -Olof H, Eriksson H, Dellborg M, Hansson P-O. Bundle-branch block in a general male population : the study of men born bundle-branch block in a general male population the study of men born 1913. Cir. 1998; 98:2494-500.

25. Landis JR, Koch GG. The measurement of observer agreement for categorical data. Biometrics. 1977;33:159.

26. Pope JH, Aufderheide TP, Ruthazer R, Woolard RH, Feldman JA, Beshansky $\mathrm{JR}$, et al. Missed diagnoses of acute cardiac ischemia in the emergency department. N Engl J Med. 2000;342:1163-70.

27. Storey RF, Rowley JM. Electrocardiogram interpretation as a basis for thrombolysis. J R Coll Physicians Lond. 1997;31:536-40.

28. Brady WJ, Perron A, Ullman E. Errors in emergency physician interpretation of ST-segment elevation in emergency department chest pain patients. Acad Emerg Med. 2000;7:1256-60

29. Montgomery H, Hunter S, Morris S, Naunton-Morgan R, Marshall RM. Interpretation of electrocardiograms by doctors. BMJ. 1994;309:1551.

30. Salerno SM, Alguire PC, Waxman HS. Competency in interpretation of 12Lead electrocardiograms: a summary and appraisal of published evidence. Ann Intern Med. 2003:751-60.

31. Gómez-Polo JC, Higueras Nafría J, Martínez-Losas P, Cañadas-Godoy V, Bover-Freire R, Pérez-Villacastín J. Escaso conocimiento entre los médicos no cardiólogos de patrones electrocardiográficos asintomáticos potencialmente letales y subestimación de su gravedad. Rev Esp Cardiol. 2017;70:507-8.

32. Begg G, Willan K, Tyndall K, Pepper C, Tayebjee M. Electrocardiogram interpretation and arrhythmia management: a primary and secondary care survey. Br J Gen Pract. 2016;66:e291-6.

33. Brilakis ES, Wright RS, Kopecky SL, Reeder GS, Williams BA, Miller WL. Bundle branch block as a predictor of long-term survival after acute myocardial infarction. Am J Cardiol. 2001;88:205-9.

34. Abdel-Qadir HM, Tu JV, Austin PC, Wang JT, Lee DS. Bundle branch block patterns and long-term outcomes in heart failure. Int J Cardiol. 2011;146: 213-8 Available from: http://www.ncbi.nlm.nih.gov/pubmed/20202707.

35. Mueller C, Laule-Kilian K, Klima T, Breidthardt T, Hochholzer W, Perruchoud $\mathrm{AP}$, et al. Right bundle branch block and long-term mortality in patients with acute congestive heart failure. J Intern Med. 2006;260:421-8.

Ready to submit your research? Choose BMC and benefit from:

- fast, convenient online submission

- thorough peer review by experienced researchers in your field

- rapid publication on acceptance

- support for research data, including large and complex data types

- gold Open Access which fosters wider collaboration and increased citations

- maximum visibility for your research: over $100 \mathrm{M}$ website views per year

At $\mathrm{BMC}$, research is always in progress.

Learn more biomedcentral.com/submissions 